\title{
A unifying perspective on neuromodulatory effects on signal transmission and plasticity in D1-dominant MSN neurons
}

\author{
Simon M Vogt ${ }^{1,2^{*}}$, Ulrich G Hofmann ${ }^{1}$ \\ From Twenty Second Annual Computational Neuroscience Meeting: CNS*2013 \\ Paris, France. 13-18 July 2013
}

How could phasic variations in dopamine level affect the learning outcome of a spiking neural network? How may neuromodulation affect the network's instantaneous response to simultaneously arriving glutamatergic inputs? How may this depend on the brain regions involved?

In our spiking phenomenological model for signal transmission across the synapse and along the dendritic tree, we propose a new approach for the influence of dopamine-like neuromodulators on the ascribed aspects, which unifies diverging views on its role in (reinforcement) learning and (attentional) contrast.

We call into question the common practice of simulating dopaminergic influence on an STDP rule as a third factor, and instead show how an instantaneous effect of a dopamine-like neuromodulator on postsynaptic activity can also lead to reinforced learning outcomes.

As the phasic change of neuromodulator needs to be present during glutamatergic transmission in our model, we do not account for delayed reward as stated in the distal reward problem. Instead, we assume an involvement of hippocampus and cortical working memory for long delays of reward. However, as our transmission-based model does not interfere with the standard two-factor STDP rule, it may be freely combined with existing extensions to STDP if needed.

\section{Author details}

${ }^{1}$ AG Neuroelectronic Systems, University Clinic Freiburg, 79108 Freiburg, Germany. ${ }^{2}$ Institute for Signal Processing, University of Lübeck, 23562 Lübeck, Germany.

Published: 8 July 2013

\footnotetext{
* Correspondence: vogt@isip.uni-luebeck.de

${ }^{1}$ AG Neuroelectronic Systems, University Clinic Freiburg, 79108 Freiburg, Germany

Full list of author information is available at the end of the article
}

\section{References}

1. Schultz W, Dayan P, Montague PR: A neural substrate of prediction and reward. Science 1997, 275(5306):1593.

2. Berridge $\mathrm{KC}$, Robinson TE: What is the role of dopamine in reward: hedonic impact, reward learning, or incentive salience? Brain research Brain research reviews 1998, 28(3):309-369.

3. Nicola SM, Hopf FW, Hjelmstad GO: Contrast enhancement: a physiological effect of striatal dopamine? Cell and tissue research 2004, 318(1):93-106.

4. Thurley K, Senn W, Lüscher HR: Dopamine increases the gain of the input-output response of rat prefrontal pyramidal neurons. Journal of neurophysiology 2008, 99(6):2985-2997.

5. Kroener S, Chandler LJ, Phillips PEM, Seamans JK: Dopamine modulates persistent synaptic activity and enhances the signal-to-noise ratio in the prefrontal cortex. PloS One 2009, 4(8):6507.

6. Masquelier T, Guyonneau R, Thorpe SJ: Spike timing dependent plasticity finds the start of repeating patterns in continuous spike trains. PloS one 2008, 3(1):1377.

7. Shen $W$, Flajolet $M$, Greengard $P$, Surmeier DJ: Dichotomous dopaminergic control of striatal synaptic plasticity. Science 2008, 321(5890):848-851.

8. Morrison A, Diesmann M, Gerstner W: Phenomenological models of synaptic plasticity based on spike timing. Biological cybernetics 2008, 98(6):459-478

9. Izhikevich EM: Solving the distal reward problem through linkage of STDP and dopamine signaling. Cerebral cortex 2007, 17(10):2443-2452.

10. Vogt SM, Hofmann UG: Neuromodulation of STDP through short-term changes in firing causality. Cognitive Neurodynamics 2012, 6(4):353-366.

doi:10.1186/1471-2202-14-S1-P172

Cite this article as: Vogt and Hofmann: A unifying perspective on neuromodulatory effects on signal transmission and plasticity in

D1-dominant MSN neurons. BMC Neuroscience 2013 14(Suppl 1):P172.

\section{C) Biomed Central}

(c) 2013 Vogt and Hofmann; licensee BioMed Central Ltd. This is an Open Access article distributed under the terms of the Creative Commons Attribution License (http://creativecommons.org/licenses/by/2.0), which permits unrestricted use, distribution, and reproduction in any medium, provided the original work is properly cited. 